\title{
Experimental Investigation on Turbulent Flow Heat Transfer Enhancement in a Horizontal Circular Pipe using internal threads of varying depth
}

\author{
Pankaj N. Shrirao ${ }^{1}$, Dr. Rajeshkumar U. Sambhe ${ }^{2}$, Pradip R. Bodade ${ }^{3}$ \\ ${ }^{1,2,3}$ Department of Mechanical Engineering Jawaharlal Darda Institute of Engg. \& Technology \\ M.I.D.C. Area, Lohara, Yavatmal-445001 Maharashtra, India.)
}

\begin{abstract}
The present work focuses on Experimental investigation of heat transfer and friction factor characteristics of horizontal circular pipe using internal threads of pitch $100 \mathrm{~mm}, 120 \mathrm{~mm}$ and $160 \mathrm{~mm}$ with air as the working fluid. The transitional flow regime is selected for this study with the Reynolds number range 7,000 to 14,000. The horizontal aluminum pipe was subjected to constant and uniform heat flux. The experimental data obtained were compared with those obtained from plain Horizontal pipe. The effects of internal threads of varying depth on heat transfer and friction factor were presented. Based on the same pumping power consumption, the pipe with internal threads possesses the highest performance factors for turbulent flow. The heat transfer coefficient enhancement for internal threads is higher than that for plain pipe for a given Reynolds number. The use of internal threads improved the performance of horizontal circular pipe.

Keywords - Enhancement, internal threads, heat transfer and turbulent flow.
\end{abstract}

\section{INTRODUCTION}

Heat exchangers are used in different processes ranging from conversion, utilization \& recovery of thermal energy in various industrial, commercial \& domestic applications. Some common examples include steam generation \& condensation in power \& cogeneration plants; sensible heating \& cooling in thermal processing of chemical, pharmaceutical \& agricultural products; fluid heating in manufacturing \& waste heat recovery etc. Increase in Heat exchanger's performance can lead to more economical design of heat exchanger which can help to make energy, material \& cost savings related to a heat exchange process. The need to increase the thermal performance of heat exchangers, thereby effecting energy, material \& cost savings have led to development \& use of many techniques termed as Heat transfer Augmentation. These techniques are also referred as Heat transfer Enhancement or Intensification. Augmentation techniques increase convective heat transfer by reducing the thermal resistance in a heat exchanger. Use of Heat transfer enhancement techniques lead to increase in heat transfer coefficient but at the cost of increase in pressure drop. So, while designing a heat exchanger using any of these techniques, analysis of heat transfer rate \& pressure drop has to be done. Apart from this, issues like long-term performance \& detailed economic analysis of heat exchanger has to be studied. To achieve high heat transfer rate in an existing or new heat exchanger while taking care of the increased pumping power, several techniques have been proposed in recent years.

Generally, heat transfer augmentation techniques are classified in three broad categories: active methods, passive method and compound method. A compound method is a hybrid method in which both active and passive methods are used in combination. The compound method involves complex design and hence has limited applications. M. Sozen and T.M. Kuzay numerically studied the enhanced heat transfer in round tubes filled with rolled copper mesh at Reynolds number range of 5,000-19,000. With water as the energy transport fluid and the tube being subjected to uniform heat flux, they reported up to ten fold increase in heat transfer coefficient with brazed porous inserts relative to plain tube at the expense of highly increased pressure drop. Q. Liao and M.D. Xin carried out experiments to study the heat transfer and friction characteristics for water, ethylene glycol and ISOVG46 turbine oil flowing inside four tubes with three dimensional internal extended surfaces and copper continuous or segmented twisted tape inserts within Prandtl number range from 5.5 to 590 and Reynolds numbers from 80 to 50,000. They found that for laminar flow of VG46 turbine oil, the average Stanton number could be enhanced up to 5.8 times with friction factor increase of 6.5 fold compared to plain tube. D. Angirasa performed experiments that proved augmentation of heat transfer by using metallic fibrous materials with two different porosities namely $97 \%$ and $93 \%$. The experiments were carried out for different Reynolds numbers $(17,000-29,000)$ and power inputs $(3.7$ and $9.2 \mathrm{~W})$. The improvement in the average Nusselt number was about 3-6 times in comparison with the case when no porous material was used. Fu et al. experimentally demonstrated that a channel filled with high conductivity porous material subjected to oscillating flow is a new and effective method of cooling electronic devices. The experimental investigations of Hsieh and Liu reported that Nusselt numbers were between four and two times the bare values at low Re and high Re 
respectively. Bogdan and Abdulmajeed et al. numerically investigated the effect of metallic porous materials, inserted in a pipe, on the rate of heat transfer. The pipe was subjected to a constant and uniform heat flux. The effects of porosity, porous material diameter and thermal conductivity as well as Reynolds number on the heat transfer rate and pressure drop were investigated. The results were compared with the clear flow case where no porous material was used. The results obtained lead to the conclusion that higher heat transfer rates can be achieved using porous inserts at the expense of a reasonable pressure drop. Smith et. al. investigated the heat transfer enhancement and pressure loss by insertion of single twisted tape, full length dual and regularly spaced dual twisted tapes as swirl generators in round tube under axially uniform wall heat flux conditions. Chinaruk Thianpong et. al. experimentally investigated the friction and compound heat transfer behavior in dimpled tube fitted with twisted tape swirl generator for a fully developed flow for Reynolds number in the range of 12000 to 44000. Whitham studied heat transfer enhancement by means of a twisted tape insert way back at the end of the nineteenth century. Date and Singham numerically investigated heat transfer enhancement in laminar, viscous liquid flows in a tube with a uniform heat flux boundary condition. They idealized the flow conditions by assuming zero tape thickness, but the twist and fin effects of the twisted tape

were included in their analysis. Saha et al. have shown that, for a constant heat flux boundary condition, regularly spaced twisted tape elements do not perform better than full-length twisted tape because the swirl breaks down in-between the spacing of a regularly twisted tape. Rao and Sastri, while working with a rotating tube with a twisted tape insert, observed that the enhancement of heat transfer offsets the rise in the friction factor owing to rotation. Sivashanmugam et. al. and Agarwal et.al. studied the thermo-hydraulic characteristics of tape-generated swirl flow. Peterson et al. experimented with high-pressure (8-16 MPa) water as the test liquid in turbulent flow with low heat fluxes and low wall-fluid temperature differences typical of a liquid-liquid heat exchanger.

The present experimental study investigates the increase in the heat transfer rate between a pipes heated with a constant uniform heat flux with air flowing inside it using internal threads of varying pitch. As per the available literature, the enhancement of heat transfer using internal threads in turbulent region is limited. So, the present work has been carried out with turbulent flow (Re number range of 7,000-14,000) as most of the flow problems in industrial heat exchangers involve turbulent flow region.

\subsection{Experimental Setup}

\section{EXPERIMENTAL WORK}

The apparatus consists of a blower unit fitted with a pipe, which is connected to the test section located in horizontal orientation. Nichrome bend heater encloses the test section to a length of $50 \mathrm{~cm}$. Three thermocouples T2, T3 and T4 at a distance of $15 \mathrm{~cm}, 30 \mathrm{~cm}$ and $45 \mathrm{~cm}$ from the origin of the heating zone are embedded on the walls of the pipe and two thermocouples are placed in the air stream, one at the entrance (T1) and the other at the exit (T5) of the test section to measure the temperature of flowing air as shown in Fig. 1. The pipe system consists of a valve, which controls the airflow rate through it and an orifice meter to find the volume flow rate of air through the system. The diameter of the orifice is $1.4 \mathrm{~cm}$ and coefficient of discharge is 0.64. The two pressure tapings of the orifice meter are connected to a water U-tube manometer to indicate the pressure difference between them. Input to heater is given through dimmer stat. The test tube of $110 \mathrm{~mm}$ thickness was used for experimentation. Display unit consists of voltmeter, ammeter and temperature indicator. The circuit was designed for a load voltage of $0-220 \mathrm{~V}$; with a maximum current of $10 \mathrm{~A}$. Difference in the levels of manometer fluid represents the variations in the flow rate of air. The velocity of airflow in the tube is measured with the help of orifice plate and the water manometer fitted on board.

\subsection{Procedure}

Air was made to flow though the test pipe by means of blower motor. A heat input of $60 \mathrm{~W}$ was given to the nichrome heating wire wound on the test pipe by adjusting the dimmer stat. The test pipe was insulated in order to avoid the loss of heat energy to the surrounding. Thermocouples 2 to 4 were fixed on the test surface and thermocouples 1 and 5 were fixed inside the pipe. The readings of the thermocouples were observed every 5 minutes until the steady state condition was achieved. Under steady state condition, the readings of all the five thermocouples were recorded. The experiments were repeated for four different test pipes of varying pitch with constant airflow rate. The fluid properties were calculated as the average between the inlet and the outlet bulk temperature. Experiments were carried out at constant heat input and constant mass flow rate, for all the four test pipes with varying pitch. 


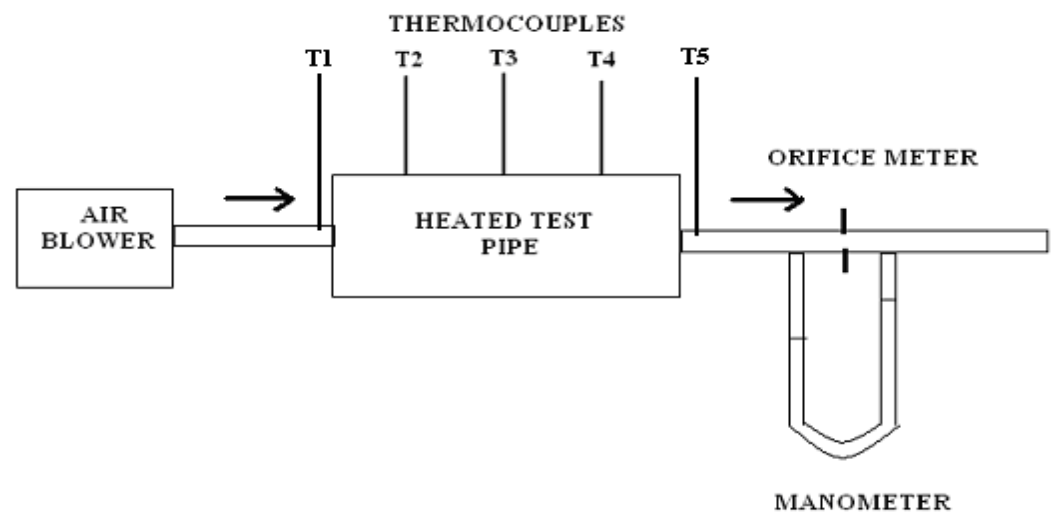

Fig. 1 Experimental setup layout
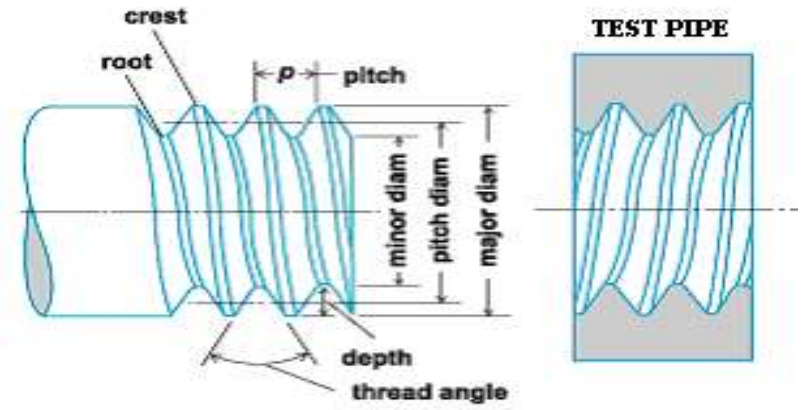

Fig. 2 Test Pipe with Internal Threads

If $\mathrm{p}=$ pitch of the thread, $\mathrm{d}=$ depth of the thread and $\mathrm{r}=$ radius at the top and bottom of the threads, then: $\mathrm{d}=$ $(0.54127 * \mathrm{p})$ and $\mathrm{r}=(0.14434 * \mathrm{p})$

\subsection{Sequence of Operations}

Experiments were carried out first on plain aluminum horizontal test pipe and then on aluminum horizontal pipe with internal threads of varying pitch.

\subsubsection{Without Internal threads}

Initially, the experiment was carried out on plain pipe without internal threads. The working fluid air flows through the pipe section with least resistance.

\subsubsection{With Internal threads of varying depth}

The internal threads were done on pipe as shown in Fig. 2. The three different test pipes of varying depth were used for experimentation. The presence of the internal threads in the pipe causes resistance to flow and increases turbulence. The mass flow rates of air and the heat input were kept constant as that of plain pipe experiment.

\section{Data reduction}

The data reduction of the measured results is summarized in the following procedures:

$$
\begin{array}{ll}
T_{s}=\left(T_{2}+T_{3}+T_{4}\right) / 3 & -(\text { Equation I ) } \\
T_{b}=\left(T_{1}+T_{5}\right) / 2 & - \text { (Equation II ) }
\end{array}
$$

Discharge of air,

$$
Q=C_{d} * A_{l} * A_{2} * \sqrt{ }\left(2 g h_{\text {air }}\right) / \sqrt{ }\left(A_{l}{ }^{2}-A_{2}{ }^{2}\right) \quad \text { - (Equation III ) }
$$

Equivalent height of air column,

$$
h_{\text {air }}=\left(\rho_{w} * h_{w}\right) / \rho_{w}
$$

Velocity of air flow,

$V=(Q / A)$

- (Equation V) 
Where $\mathrm{A}=$ convective heat transfer area $(\Pi * \mathrm{D} * \mathrm{~L})$,

Where $\mathrm{D}=$ inner diameter of pipe

$$
\operatorname{Re}=(\rho * V * D) / \mu
$$

$\mathrm{L}=$ Length of pipe

Total Heat Transfer

$$
\begin{aligned}
& Q=Q c+Q r \\
& Q=m C_{p}\left(T_{1}-T_{5}\right)
\end{aligned}
$$

Where $\mathrm{m}=$ mass flow of air

$\mathrm{Qc}=$ Convective Heat Transfer

$\mathrm{Qr}=$ Radiation Heat Transfer

$$
\begin{aligned}
& Q r=\sigma A \varepsilon\left(T_{s}{ }^{4}-T_{b}{ }^{4}\right) \\
& h=(Q-Q r) /\left(A\left(T_{s}-T_{b}\right)\right.
\end{aligned}
$$

Experimental Nusselt number

$N u=h^{*}(D / K)$

- (Equation XI)

Nusselt numbers calculated from the experimental data for plain tube were compared with the correlation recommended by Dittus-Boelter.

$$
\text { Theoretical Nusselt number } \quad N u=0.023 \operatorname{Re}^{0.8} \operatorname{Pr}^{0.4}
$$

In straight pipe lengths, Pressure drop $(\Delta \mathrm{P})$ can be calculated using the Darcy Equation

$\mathrm{f}=$ Darcy friction factor

$$
\Delta P_{\text {Friction }}=\frac{\text { f. } L_{\text {Pipe }}}{d_{\text {Pipe }}} \frac{\rho \cdot u^{2}}{2}
$$

\section{RESULTS AND DISCUSSION}

Experimentally determined Nusselt number values for plain horizontal pipe (without internal threads) are compared with Dittus-Boelter correlation. Figure 3 shows the comparison between Nusselt numbers obtained experimentally, analytically and by using Dittus-Boelter equation for plain pipe. It is observed that the value of $\mathrm{Nu}$ (experimental) is less than $\mathrm{Nu}$ (Dittus-Boelter). Actual heat carried away by air passing through the test section is the combination of convective and radioactive heat transfers. As the heat transferred by convection alone is considered while performing experimental and numerical calculations (Equation VIII), it can be expected that $\mathrm{Nu}$ (experimental) is less than $\mathrm{Nu}$ (Dittus-Boelter). Figure 4 shows the validation of numerical results for friction factor of plain pipe against existing correlation (Equation XI). Figure 5 shows the variation of friction factor Vs Reynolds number for the test pipe using internal threads of varying depth. The friction factor for the test pipe using internal threads of varying depth is more than that for plain test pipe. Also friction factor decreases with increase in Reynolds number for a given depth. This shows that the turbulence formation advanced due to artificial turbulence exerted by internal threads. The friction factor is increases with increasing the depth. This is due to more intense swirl flow in case of more depth. Figure 6 shows the variation of pressure drop with Reynolds number. Pressure drop increases with increase in Reynolds number. Maximum pressure drop is observed to be 1.06 times compared to that of plain test pipe for internal thread of depth $\mathrm{d}=$ $86.60 \mathrm{~mm}$. The large increase in the pressure drop can be attributed to the plain test pipe for internal thread of depth $\mathrm{d}=86.60 \mathrm{~mm}$, and the increased velocity associated more intense swirl flow in case of more depth. 


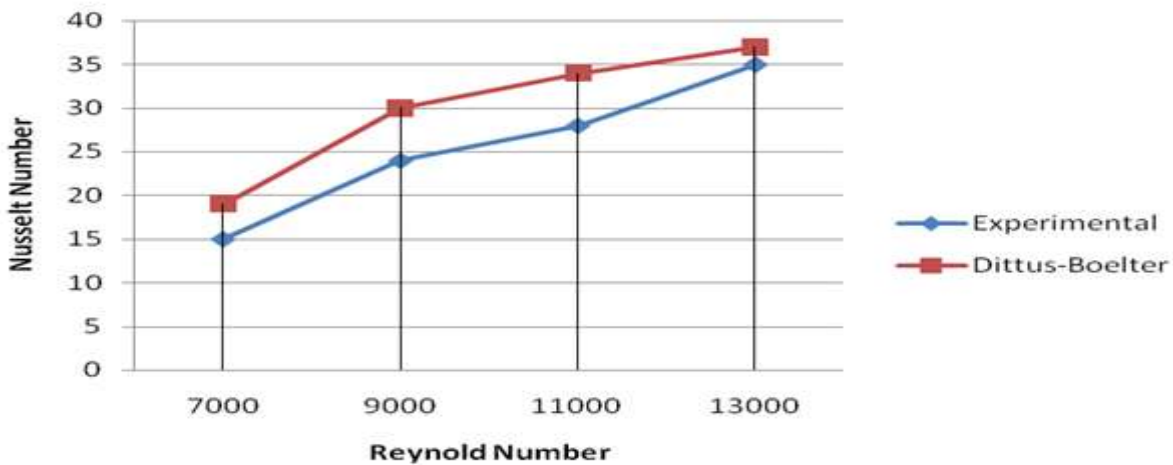

Fig. 3 Comparison between Nusselt numbers obtained experimentally, analytically by using Dittus-Boelter equation for plain pipe

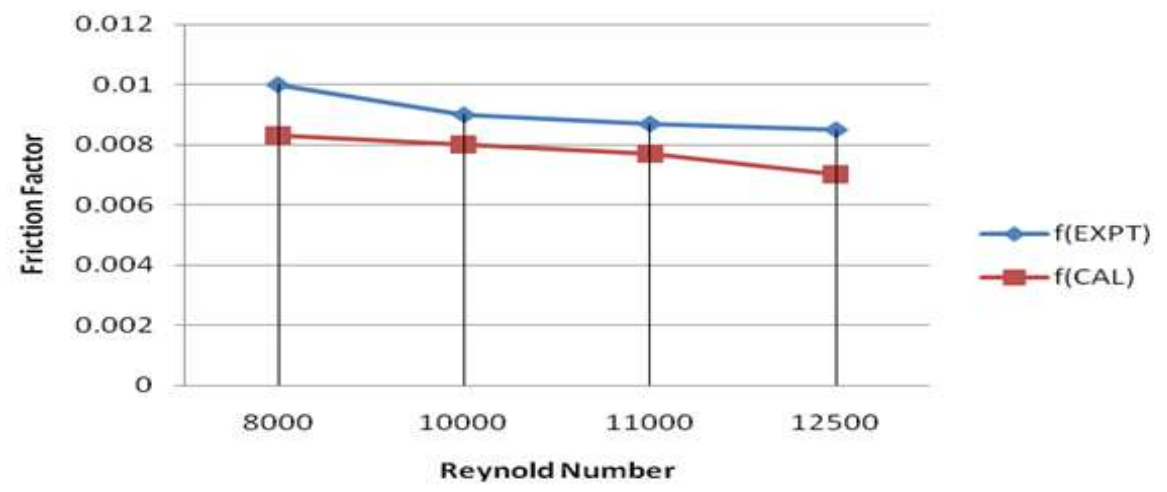

Fig. 4 Validation of numerical results for friction factor of plain pipe against existing correlation

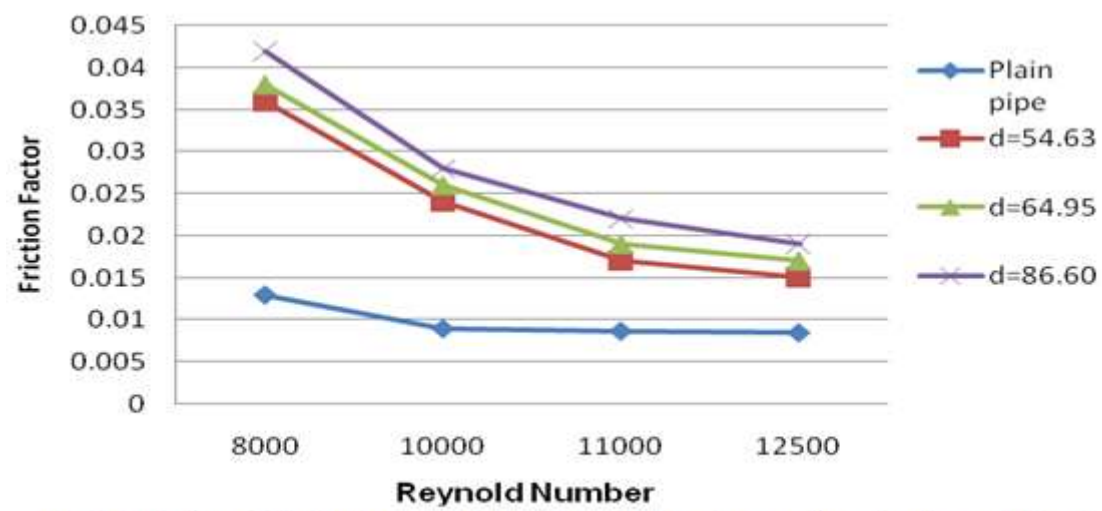

Fig. 5 Variation of friction factor Vs Reynolds number for the test pipe using internal threads of varying depth

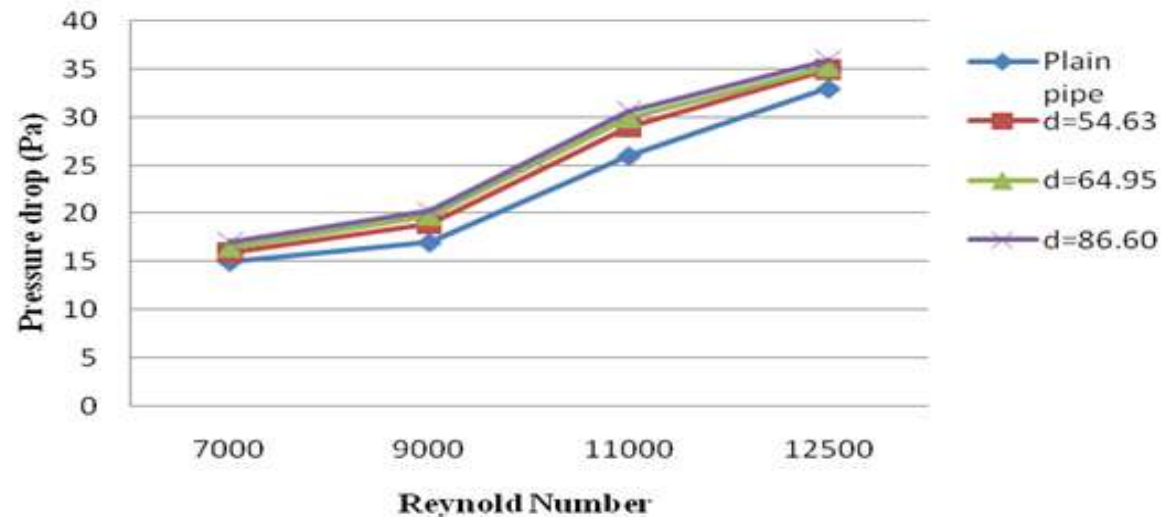

Fig. 6 Variation of pressure drop with Reynolds number 


\section{CONCLUSION}

Experimental investigations on enhancement of turbulent flow heat transfer with internal threads of varying depth in a horizontal pipe under forced convection with air flowing inside are carried out. From the experimental results, conclusions can be drawn as follows:

1. The heat transfer enhancement increases with increase in depth of internal threads due to increased turbulence of air. It is due to the swirl flow motion provided by internal threads.

2. The friction factor increases with the increase of depth of internal threads again due to swirl flow exerted by the internal threads.

3. The enhancement of Nusselt number is much higher than that of enhancement in friction factor for the same depth of internal threads that justifies the usage of internal threads in horizontal pipe.

4. The performance of horizontal pipe can be improved by the use of internal threads. The cost involved for making internal threads is minimal compared to energy efficiency improvement provided by this technique.

\section{Acknowledgements}

We are thankful to the Hon. Principal Dr. A.W. Kolhatkar and Head of Department Dr. A. B. Borade, Jawaharalal Darda Institute of Engineering and Technology, Yavatmal, Maharashtra, India for providing Mechanical Engineering Research Laboratory for Experimentation study and their moral support.

\section{REFERENCES}

[1] M. Sozen and T M. Kuzay (1996), "Enhanced heat transfer in round tubes with porous inserts", International Journal Heat and Fluid Flow, Vol. 17, pp.124-129

[2] Q. Liao and M.D. Xin (2000), "Augmentation of convective heat transfer inside tubes with three-dimensional internal extended surfaces and twisted-tape inserts", Chemical Engineering Journal, Vol. 78, pp. 95-105

[3] D. Angirasa (2001), "Experimental investigation of forced convection heat transfer augmentation with metallic porous materials", International Journal of Heat Mass Transfer, pp. 919-922

[4] H.L. Fu, K.C. Leong, X.Y. Huang and C.Y. Liu (2001), "An experimental study of heat transfer of a porous channel subjected to oscillating flow", ASME Journal of Heat Transfer, Vol. 123, pp.162-170.

[5] S.S Hsieh, M.H. Liu, H.H. Tsai (2003), "Turbulent heat transfer and flow characteristic in a horizontal circular tube with strip-type inserts part-II (heat transfer)", International Journal of Heat and Mass Transfer, Vol. 46, pp.837-849.

[6] B.I. Pavel and A.A. Mohamad (2004), "An experimental and numerical study on heat transfer enhancement for gas heat exchangers fitted with porous media”, International Journal of Heat and Mass Transfer, Vol. 47, pp.4939-4952.

[7] Smith Eiamsa-ard, Chinaruk Thianpong, Petpices Eiamsa-ard and Pongjet Promvonge (2009), "Convective heat transfer in a circular tube with short-length twisted tape insert", International communications in heat and mass transfer (2009).

[8] Chinaruk Thianpong, Petpices Eiamsa-ard, Khwanchit Wongcharee and Smith Eiamsaard (2009), Compound heat transfer enhancement of a dimpled tube with a twisted tape swirl generator, International Communications in Heat and Mass Heat and Mass Transfer, Vol. 36, pp. 698-704.

[9] Whitham, J. M (1896), The effects of retarders in fire tubes of steam boilers, Street Railway, Vol. 12(6), pp. 374.

[10] Date, A. W. and Singham, J. R. (1972), "Numerical prediction of friction and heat transfer characteristics of fully developed laminar flow in tubes containing twisted tapes", Trans. ASME, Journal of Heat Transfer, Vol. 17, pp. 72

[11] S.K.Saha, U.N.Gaitonde and A.W. Date (1989), "Heat transfer and pressure drop characteristics of laminar flow in a circular tube fitted with regularly spaced twisted-tape elements", Journal of Exp. Thermal Fluid Sci., Vol. 2, pp.310-322.

[12] Rao, M. M. and Sastri, V. M. K. (1995), "Experimental investigation for fluid flow and heat transfer in a rotating tube twisted tape inserts", International Journal of Heat and Mass Transfer, Vol.16, pp.19-28.

[13] Sivashanmugam, P. and Suresh, S. (2007), "Experimental studies on heat transfer and friction factor characteristics of turbulent flow through a circular tube fitted with regularly spaced helical screw tape inserts", Experimental Thermal and Fluid Science, Vol. 31, pp. 301-308.

[14] Agarwal, S. K. and Raja Rao, M. (1996), "Heat transfer augmentation for flow of viscous liquid in circular tubes using twisted tape inserts", International Journal of Heat Mass Transfer, Vol. 99, pp.3547-3557.

[15] Peterson, S. C., France, D. M. and Carlson, R. D. (1989), "Experiments in high-pressure turbulent swirl flow", Trans. ASME, Journal of Heat Transfer, Vol. 108, pp.215-218. 